\title{
Penerapan Algoritma Convolutional Neural Network Untuk Klasifikasi Motif Citra Batik Solo
}

\author{
Tungki Ari Bowo ${ }^{1}$, Hadi Syaputra*2, Muhammad Akbar ${ }^{3}$ \\ 1,2,3 Informatics Departement, Bina Darma University, Palembang, Indonesia \\ Email: ${ }^{1}$ aribowo.ab7@gmail.com, ${ }^{2}$ hadisyaputra@binadarma.ac.id, \\ ${ }^{3}$ muhammad.akbar@binadarma.ac.id
}

\begin{abstract}
Abstrak
Batik adalah warisan kebudayaan Indonesia yang telah menjadi ciri khas masyarakat Indonesia. Batik memiliki banyak motif dan corak dengan ciri yang berbeda disetiap corak atau motifnya. Sebagai upaya melestarikan batik, penelitian mengenai klasifikasi batik digunakan untuk mengenali motif citra batik. Untuk itu penelitian ini dilakukan menggunakan metode pembelajaran dengan data citra batik diharapkan dapat memberikan hasil klasifikasi yang akurat dan efisien dengan tingkat akurasi tinggi. Convolutional Neural Network (CNN) merupakan gabungan dari jaringan syaraf tiruan dan metode deep learning. CNN terdiri 3 layer utama yaitu Convolutional Layer, Pooling Layer, Fully Connected Layer. Pada penelitian ini menggunakan arssitektur 3 Convolutional Neural Network dan 2 Fully Connected Layer pada pembuatan system terdapat beberapa tahapan utama yaitu pengumpulan data, perancangan system, training, dan testing. Penelitian ini menggunakan data citra batik solo sebanyak 2.256 gambar yang terdiri dari 7 kelas yaitu motif Parang, Semenrante, Sidomukti, Ceplok, Kawung, Truntum, dan Buketan. Hasil dari proses learning didapatkan akurasi sebesar 99.07\% dengan loss sebesar 0,2\%. Pada proses pengujian menggunakan 745 sampel batik solo didapatkan akurasi sebesar 95\%. Sehingga dapat disimpulkan bahwa metode CNN dapat mengklasifikasi citra dengan baik.
\end{abstract}

Kata Kunci: batik, batik solo, convolutional neural network, image, deep learning.

\section{PENDAHULUAN}

Batik adalah warisan kebudayaan Indonesia yang telah menjadi ciri khas masyarakat Indonesia. Kain batik banyak digunakan untuk pakaian resmi maupun sehari-hari. Batik sendiri dianggap sebagai pakaian tradisional yang digunakan oleh masyarakat Indonesia. Pada dasarnya senibatik adalah seni melukis lilin atau cara menghias kain dengan menutupi bagian kain dengan lapisan lilin kemudian mencelupkan kain (Lestari, 2012). Oleh karena itu batik memang sangat istimewa, 


\section{Journal of Software Engineering Ampera}

Vol. 1, No. 2, June 2020 e-ISSN: 2775-2488

https://journal-computing.org/index.php/journal-sea/index

karena pada setiap motif mempunyai makna filosofi yang memiliki nilai sejarah yang panjang dan corak maupun motif batik tersebut tidak lepas dari wilayah asal daerahnya.

Untuk melestarikan warisan budaya Indonesia ini, diperlukan penelitian yang berkesinambungan. Salah satu topik penelitian yang banyak dikembangkan dalam suatu bidangilmu komputer yaituklasifikasi batik. Topik penelitian ini juga relevan dengan topik yang masih aktual yaitu ekstraksi fitur digunakan untuk mewakili karaketristik suatu gambar batik sehingga dapat mengidentifikasi gambar dengan akurat. Akan tetapi, kain batik dengan motif yang bervariasi akan menyebabkan kesulitan dalam mengidentifikasi gambar batik itu sendiri. Sehingga diperlukan suatu metode yang dapat digunakan untuk mengekstraksi fitur batik berdasarkan motifnya (Putri \& Rochmawati, 2019).

Pengetahuan tentang pengenalan jenis motif batik hanya dimiliki oleh orang-orang tertentu hal ini dikarenakan batik memiliki motif yang bervarisi dan hampir serupa disetiap daerah nya. Berdasarkan permasalahantersebut salah satu cara untukmengenali motif batik adalah dengan pengenalan pola. Metode tersebut sangatlah bisa diterapkan pada pengklasifikasian motif batik.

Dengan demikian, salah satu tantangan terpenting pada computer vision adalah pengenalan objek dimana komputer diberi gambar untuk dianalisa dan menerapkan algoritma pengenalan tertentu, tujuan utamanya adalah untuk mendeteksi objek didalam gambar. Salah satumetode yang dapat digunakan untuk pengenalan pola adalah menggunakan metode Deep Learning yaitu Convolutional Neural Network (CNN). Convolutional Neural Network (CNN) telah berhasil melakukan pengklasifikasian dalam membedakan salak yang lolos ekspor dan tidak. Input yang digunakan dalam penelitian tersebut adalah citra salak (RISMIYATI \& M.t, 2016).

Selaras dengan itu penelitianini mencoba merancang sebuah sistem pengklasifikasian motif citra batiksolo yang menggunkan algoritma Convolutional Neural Network (CNN) sebagai metode pengenalan pola khususnya klasifikasi gambar batik. Oleh karena itu penulis bertujuan memperkaya riset mengenai klasifikasi gambar citrabatik solo menggunakan metode CNN. Diharapkan Convolutional Neural Network (CNN) dapat mengenali serta mengklasifikasi batik solo berdasarkantujuh kelas motif batik yaitu, motif Parang, Buketan, Ceplok, Kawung, Truntum, Semen Rante, 


\section{Journal of Software Engineering Ampera}

Vol. 1, No. 2, June 2020 e-ISSN: 2775-2488

https://journal-computing.org/index.php/journal-sea/index

dan Sidomukti yang diharapkan dapat memberikan hasil yang lebih efisien dan akurat dengan akurasi yang cukup baik dan berguna bagi pihak yang membutuhkan.

\section{METODOLOGI PENELITIAN}

\subsection{Metode pengumpulan data}

\subsubsection{Populasi dan sampel}

Populasi merupakan suatu wilayah generalisasi yang terdiri atas obyek atau subyek yang mempunyai kualitas dan karakteristik tertentu yang telah ditetapkan oleh peneliti untuk dipelajari dan kemudian ditarik kesimpulanya (Sugiyono, 2012). Populasi dalam penelitian ini adalah motif citra batik yaitu semua data motif citra batik yang ada di indonesia. Sedangkan untuk sampel dalam penelitian ini adalah motif citra batik solo yang terdiri dari tujuh(7) jenis motif yaitu motif Parang, Buketan, Ceplok, Kawung, Truntum, Semen Rante, dan Sidomukt.

\subsubsection{Teknik Sampling}

Data primer adalah data yang digunakan dalam penelitian ini, data tersebut dikumpulkan dari berbagai bersumber dari internet. Pengumpulan data primer adalah dengan mengunduh data citra yang telah ada diinternet. Dalam penentuan sampel adapun cara yang digunakan yaitu menggunakan cara purposive sampling. Hal ini dilakukan dengan cara mengabil subjek bukan didasarkan atas tujuan tertentu. Purposive sampling adalah teknik penentuan sampel dengan pertimbangan tertentu (Sugiyono, 2016).

\subsection{Metode simulasi}

Pada penelitian ini metode yang digunakan adalah metode simulasi. Berikut ini adalah langkah-langkah metode simulasi :

\subsubsection{Formulasi Masalah (Problem Formulation)}

Di dalam tahapan ini, penulis melakukan identifikasi masalah berdasarkan penelitianpenelitian yang berkaitan dengan metode Convolutional Neural Network (CNN) dan Image Classification pada Deep Learning. Pada penelitian yang sudah ada belum ada yang membahas permasalahan sistem pengklasifikasian motif citra batik solo menggunakan metode (CNN) 


\section{Journal of Software Engineering Ampera}

Vol. 1, No. 2, June 2020 e-ISSN: 2775-2488

https://journal-computing.org/index.php/journal-sea/index

\subsubsection{Model Pengkonsepan (Conseptual Model)}

Pada tahap ini, penulis merencanakan model konsep pada penelitian ini, pada penelitian ini akan melakukan pemodelan untuk mengenali pola motif batik solo pada citra gambar batik solo dengan arsitektur Convolutional Neural Network pada proses klasifikasinya. Proses pembuatan sistem nantinya akan terdapat proses ekstraksi fitur pada dataset gambar, mendapat nilai akurasi tinggi, membuat model sistem untuk mengenali motif batik, lalu dihubungkan dengan interface yang telah dibuat. Setalah itu mendapat outnpu hasil sistem berupa motif citra yang telah di input dan dikenali oleh sistem.

\subsubsection{Pengumpulan Data Masukan/Keluaran (Collection input/Output Data)}

Dalam tahapan ini, penulis melakukan pengumpulan data yang dibutuhkan untuk membuat model sistem untuk pengklasifikasian motif batik ini. Data yang dikumpulkan berupa gambar batik solo berdasarkan 7 kelas yaitu motif batik Parang, Buketan, Ceplok, Kawung, Truntum, Semen Rante, dan Sidomukti. Data kemudian dikumpulkan dari berbagai sumber dari internet. Data awal berupa gambar batik. Kemudian penulis memperbanyak data dengan memotong, memutar rotasi dan dibolak balik menjadi motif yang diperlukan sesuai kelas yang telah di tentukan. Setelah seluruh gambar dikumpulkan dan dilakukan pemilihan dari gambar yang berualitas baik, data gambar tersebut nantinya akan dibagi menjadi data latih dan data uji. Pada proses pembuatan model, untuk mencapai nilai akurasi yang diinginkan, setelah data dilatih dan diuji. Dan telah mendapat jumlah yang diinginkan kemudian dibuat model dengan metode Convolusional Neural Network (CNN).

\subsubsection{Preprocessing}

Pada tahap ini data yang sudah ada kemudian masuk ketahap preprocessing. Data yang masuk kemudian diresize, yang bertujuan untuk menyamakan ukuran gambar. Data yang sudah diresize kemudian melalui proses segmentasi citra dimana data diproses untuk menentukan deteksi tepi, yang bertujuan untuk mengenali objek yang ada dalam data.

\subsubsection{Pemodelan}

Dalam tahapan ini penulis melakukan pembuatan model dari dataset yang ada untuk mengenali gambar dan proses klasifikasi mengunakan metode deep leraning yang menggunaan algoritma Convolutional Neural network agar sistem dapat mengenali citra motif batik. 


\section{Journal of Software Engineering Ampera}

Vol. 1, No. 2, June 2020 e-ISSN: 2775-2488

https://journal-computing.org/index.php/journal-sea/index

\subsubsection{Pelatihan Pengujian}

pada tahap pelatihan dan pengujian yaitu menggunakan metode Convolutional Neural Network. Pada tahapan ini, data yang dikumpulkan dalam bentuk citra dibagi menjadi menjadi data latih dan data uji. Untuk mendapatkan model yang ingin dibuat dibutuhkan suatu analisis dari data latih. Setelah data dilatih, dilakukan tahap selanjutnya dengan menghitung nilai lossdan akurasi dari model-model yang dihasilkan dari data uji. Data uji berguna untuk mengetahui nilai akurasi yang dihasilkan dari model yang telah dilatih. Penentuan nilai dari data Epoch dimana suatu perulangan dari proses pengujian pada satu kali sesi lewatkan guna untuk mendapatkan error terkecil dan menghasilkan kinerja yang baik untuk model yang dibuat.

\subsubsection{Eksperimental(Eksperimentation)}

Selanjutnya penulis melakukan tahap eksperimentasi yaitu mencoba keberhasilan model yang dibuat. Penulis menginput dokumen batik yang berformat jpg yang telah disiapkan oleh penulis, lalu sistem akan memproses inputan tersebut. Setelah diproses melalui model yang dibuat, keluarlah hasil dari inputan tersebut berupa kelas yang telah ditentukan.

\subsubsection{Analisis Output (Output Analisis)}

Pada tahap ini penulis melakukan analisa terhadap output atau keluaran berdasarkan skenario yang dilakukan apakah sesusai dengan inputan. Selain itu juga pada tahap ini akan menampilkan hasil keluaran dengan inputan dokumen.

\subsection{Metode Analisis data}

dalam metode analisis data yang digunakan dalam penelitian ini adalah menggunakan metode Deep Learning yaitu Convolutional Neural Network (CNN), metode ini digunakan untuk klasifikasi objec recognition pada motif batik solo.

\subsection{Diagram Alur Penelitian}

Seperti yang diperlihatkan pada gambar 1 alur pengerjaan penelitian ini dimulai dari konsep model yaitu menentukan konsep yang dibuat. Kemudian pengumpulan data sampel yang digunakan sebagai input untuk data training, validasi dan pengujian/tes. Kemudian merancang jaringan dengan metode 


\section{Journal of Software Engineering Ampera}

Vol. 1, No. 2, June 2020 e-ISSN: 2775-2488

https://journal-computing.org/index.php/journal-sea/index

CNN untuk melakukan klasifikasi pada motif citra batik solo. Rancangan jaringan CNN diaplikasikan dengan data training. Sehingga komputer dapat belajar mengenali objek. Untuk mengetahui pembelajaran jaringan yang dihasilkan menghasilkan nilai yang sangat baik dalam membedakan jenis objek batik solo, maka jaringan tersebut kemudian di uji coba terhadap data validasi. Jika data validasi mendapatkan hasil yang baik maka jaringan dapat digunakan untuk klasifikasi pada data tes.

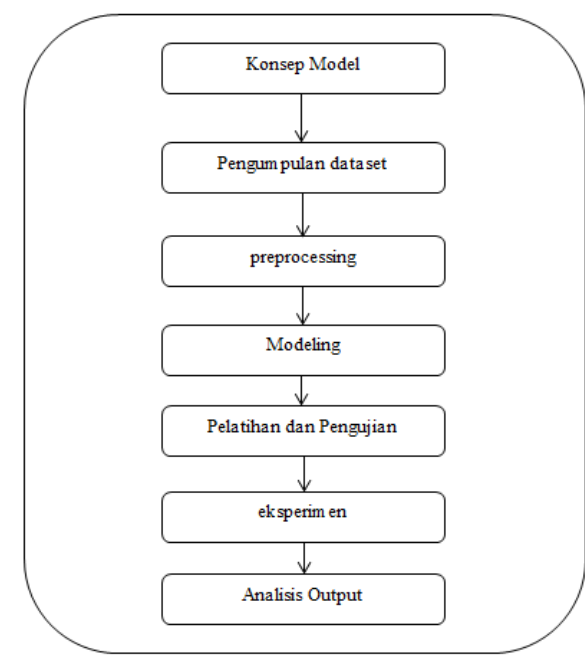

Gambar 1. Diagram Alur

\section{RESULTS AND DISCUSSION}

\subsection{Pelabelan}

Setelah dataset terkumpul dan dirapikan dalam folder sesuai kelas yang telah melewati tahap preprocessing, selanjutnya dataset diberi label sesuai kelas. Pelabelan dimulai dari label 1 sampai 7 label dengan dtype=float32 kemudian di mapping berdasarkan kelas. Sehingga menghasilkan label dan kelas sebagai berikut:

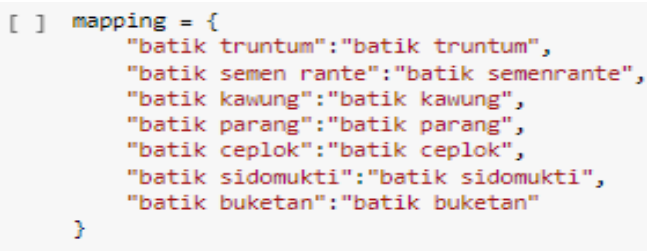

Gambar 2. Pelabelan 


\section{Journal of Software Engineering Ampera}

Vol. 1, No. 2, June 2020 e-ISSN: 2775-2488

https://journal-computing.org/index.php/journal-sea/index

\subsection{Membagi Dataset Untuk Dilatih dan Diuji dari Dataset}

Proses selanjutnya adalah dataset yang telah ada akan dibagi menjadi data latih dan data uji menggunakan model sklearn yang sudah ada pada library python. pada penelitian ini digunakan library sklearn karena library ini memudahkan pemrograman karena lebih sedikit baris kode dibandingkan dengan library lainnya seperti tensorflow atau numpy. Library sklearn juga dapat digunakan untuk clustering atau pengelompokan data dengan karakteristik yang sama ke suatu wilayah yang sama dan data dengan karakteristik yang berbeda ke wilayah yang lain. Fungsi train_test_split di masukkan pada program guna memisahkan array atau matrik menjadi data latih dan data test secara acak. Pada proses ini digunakan test_size sebesar 0.33 dan random size sebanyak 42 .

\subsection{Arsitektur Jaringan}

Setalah melaui tahap pelabelan dan pengambilan data training dari dataset, selanjutnya dataset akan dilatih menggunakan algoritma Convolutional Neural Network (CNN). Pada algoritma Convolutional Neural Network (CNN) pembentukan arsitektur dapat mempengaruhi hasil dan akurasi model.

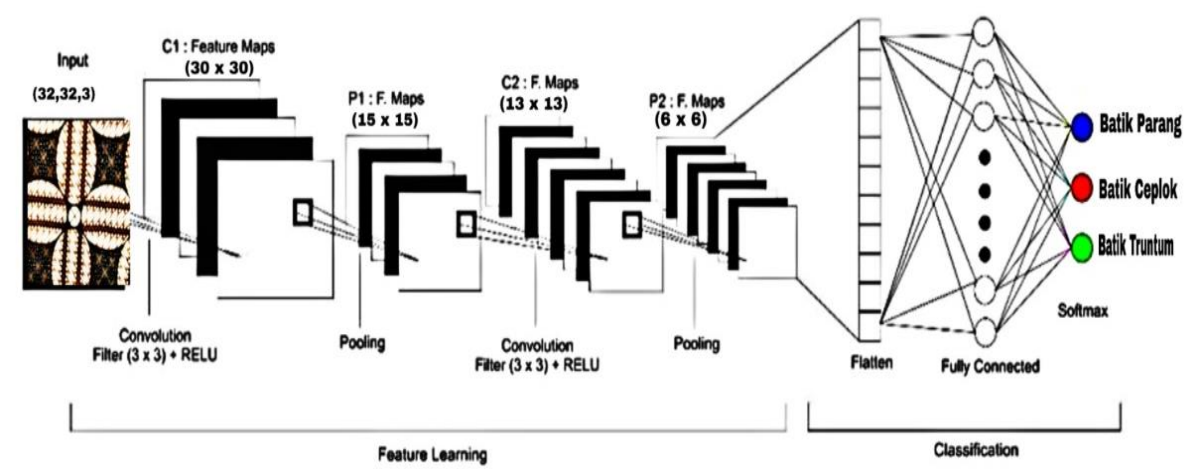

Gambar 3. Arsitektur Jaringan

Pada gambar 3 adalah arsitektur jaringan pada proses training untuk menghasilkan model yang optimal. Penelitian ini menggunakan input berukuran $32 \times 32 \times 3$, yang bertujuan untuk membandingkan nilai akurasi berdasarkan ukuran gambarnya. Penjelasan untuk gambar arsitektur diatas dapat dijelaskan seperti seperti penjelasan dibawah ini:

1) Pada proses pertama yaitu proses konvolusi digunakan kernel berukuran $3 \times 3$ dan jumlah dengan jumlah filter sebanyak 32 filter, proses konvolusi ini adalah 


\section{Journal of Software Engineering Ampera}

Vol. 1, No. 2, June 2020 e-ISSN: 2775-2488

https://journal-computing.org/index.php/journal-sea/index

proses kombinasi antara dua buah matrik yang berbeda untuk menghasilkan suatu nilai matriks yang baru. Setelah proses konvolusi, maka ditambahkan sebuah aktivasi fungsi RELU (Retrified Linier Unit). Fungsi aktivasi ini bertujuan untuk mengubah nilai negatif menjadi nol(menghasilkan nilai negative dalam sebuah matriks hasil konvolusi). Hasil konvolusi ini memiliki ukuran baru yakni $30 \times 30$.

2) Proses pooling pertama. Pooling merupakan pengurangan ukuran matriks dengan menggunakan operasi pooling. Pada dasarnya pooling layer terdiri dari suatu filter dengan ukuran tertentu yang secara bergantian bergeser pada seluruh area feature map. Penelitian ini mengunakan maxpooling untuk mendapatkan nilai matriks yang baru hasil dari proses pooling. Berdasarkan hasil pooling menghasilkan matriks baru berukuran $15 \times 15$ dari input hasil konvolusi pertama yang berukuran $30 \times 30$. Proses ini menggunakan kernel pooling $2 \times 2$. Untuk cara kerja max-pooling adalah mengambil nilai paling maksimum berdasakan pergerakan kernelnya sebanyak nilai stride nya yaitu 2 .

3) Proses konvolusi kedua adalah meneruskan hasil dari proses pooling pertama yakni dengan input matriks dengan gambar sebesar $15 \times 15$ dengan jumlah filter yang sama dengan konvolusi pertama yakni sebanyak 32 filter dan dengan ukuran kernel $3 \times 3$. Proses konvolusi kedua sama-sama menggunakan fungsi RELU. Proses ini menghasilkan gambar berukuran $13 \times 13$.

4) Proses selanjutnya adalah proses pooling ke dua, proses ini hampir sama dengan proses pooling pertama akan tetapi memiliki perbedaan di nilai output akhir dan matriksnya. Output yang dihasilkan dari proses pooling kedua memiliki ukuran gambar sebesar $6 \times 6$

5) Proses selanjutnya adalah proses Flatten dan fully connected. Untuk tahap ini hanya menggunakan satu hiden layer pada jaringan MLP (Multi Layer perceptron). Fungsi Flatten disini berfungsi untuk mengubah output pooling layer menjadi sebuah vector. Sebelum melakukan klasifikasi atau memprediksi gambar, pada tahap ini digunakan nilai dropout. Dropout adalah sebuah teknik regulasi jaringan syaraf dengan tujuan untuk memilih beberapa neuron secara acak dan tidak akan dipakai selama proses pelatihan. Oleh sebab itu neuronneuron dibuang secara acak. Tujuan dari penelitian ini adalah mengurangi overfitting pada proses trinning. Nilai Droupout yang digunakan sebesar 0,5 engan mengeluarkan hasil yang sama $6 \times 6$

6) Proses terakhir adalah menggunakan aktivasi fungsi Softmax. Fungsi ini secara spesifik bisa digunakan pada metode klasifikasi multinominal logistic regression dan multiclass liniear discriminant analiys. 


\section{Journal of Software Engineering Ampera}

Vol. 1, No. 2, June 2020 e-ISSN: 2775-2488

https://journal-computing.org/index.php/journal-sea/index

Pada penjelasan uraian arsitektur jaringan diatas, arsitektur tersebut digunakan untuk proses trining. Sehingga dari proses training didapatkan model dari arsitektur tersebut. Berikut model yang terbentuk:

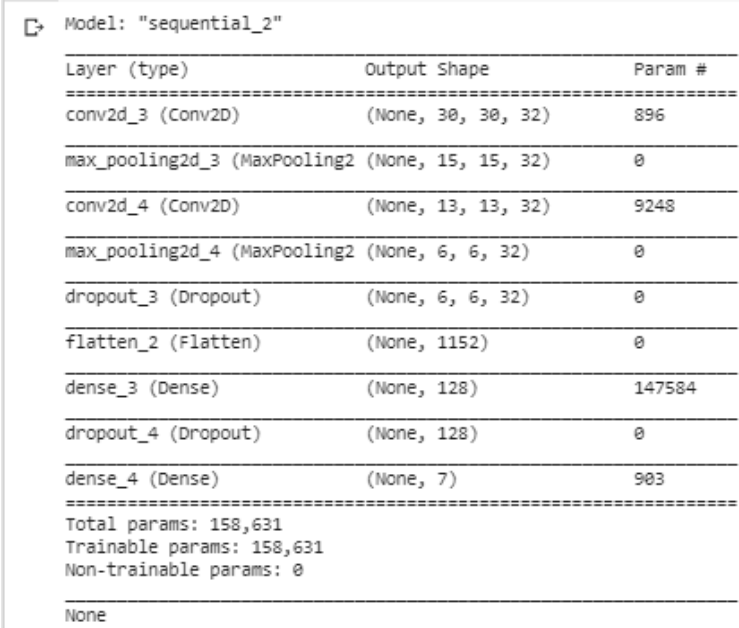

Gambar 4. Model CNN

Gambar 4. adalah model yang terbentuk dari hasil training. Total parameter yang terbentuk dari model sebanyak 158,631 neuron

\subsubsection{Proses Convolusi Layer}

Proses selanjutnya adalah proses konvolusi yang terjadi berdasarkan arsitektur jaringan yang telah dibahas diatas.

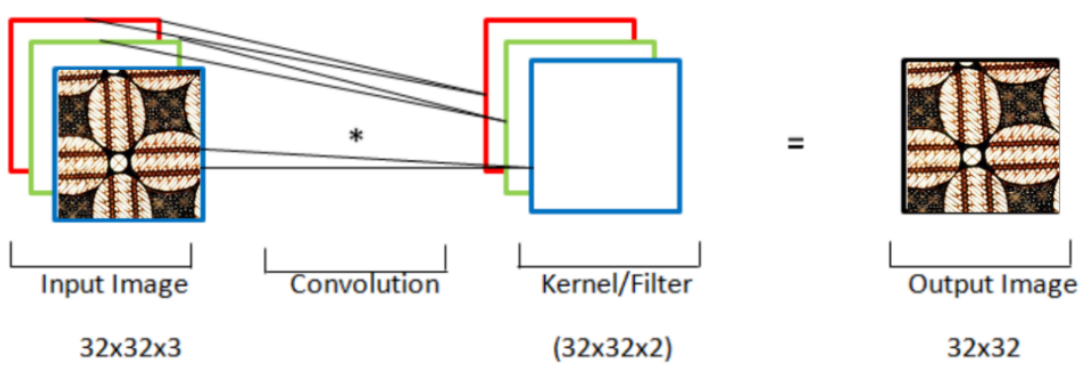

Gambar 5. Proses Konvolusi

Konvolusi adalah proses penggabungan dua digit angka pada suatu gambar sehingga menghasilkan digit angka yang baru, dengan kata lain gambar tersebut dimanipulasi 


\section{Journal of Software Engineering Ampera}

Vol. 1, No. 2, June 2020 e-ISSN: 2775-2488

https://journal-computing.org/index.php/journal-sea/index

yang menggunakan external mask / subwindows untuk menghasilkan citra yang baru, angka konvolusi pada citra tersebut berbentuk matriks array. Berdasrakan gambar 3.4 digunakan input gambar sebesar 32 pixel dan gambar input teesebut mepunyai channel yaitu red,green, dan blue atau sering disebut dengan RGB.

Disetiap channel pixel mempunyai nilai matriks yang berbeda-beda. Input akan di konvolusi dengan nilai filter yang sudah ditentukan. Filter adalah blok lain atau kubus engan tinggi dan lebar yang lebih kecil namun mempunyai kedalaman yang sama yang tersapu di atas gambar dasar atau gambar asli. Filter digunakan untuk menetukan pola apa yang akan dideteksi yang selanjutnya akan dikonvolusi atau dikalikan dengan nilai pada input matriks, nilai masing-masing kolom dan baris pada matriks sangat bergantung pada jenis pola yang akan dideteksi. Jumlah filter pada konvolusi ini sebanyak 32 dengan ukuran (3×3) yang artinya gambar dihasilkan dari hasil konvolusi akan sebanyak 32 fitur map.

Berdasarkan arsitektur jaringan diatas digunakan aktivasi ReLU (Recitified Linear Unit) setelah proses konvolusi belangsung. Fungsi aktivasi sendiri adalah melakukan"treshold" dari 0 hingga infinity. Nilai yang ada pada hasil konvolusi yang bernilai negatif akan diubah dengan aktivasi ini menjadi nol dan yang lainya sampai infinity.

\subsubsection{Proses Pooling}

Polling atau penggabungan merupakan proses dari CNN dimana matriks input disederhanakan menjadi matriks yang baru. Dalam penelitian ini digunakan metode max pooling pada proses poolingnya dimana akan diambil nilai terbesar dari matriks input yang kemudian menghasilkan matriks baru sebagai outputnya. Berdasarkan penelitian (Hutchison et al., 2010) berjudul "Evaluation of Pooling Operations in Convolutional Architectures for Object Recognition" yang menunjukan bahwa max pooling lebih efektif menghasilkan hasil yang lebih baik dibaningkan dengan metode lain seperti subsampling untuk data berupa gambar. Untuk itu pada penelitian ini menggunakan max pooling didalam proses poolingnya

\subsubsection{Proses Fully Connected}

Proses terakhir adalah Fully-Connected. Hasil dari proses terakhir dari model yang ada di dalam feature extraction layer yang masih berbentuk multiimensional array, sehingga harus dilakukan "flatten" atau reshape feature map menjadi sebuah vector 


\section{Journal of Software Engineering Ampera}

Vol. 1, No. 2, June 2020 e-ISSN: 2775-2488

https://journal-computing.org/index.php/journal-sea/index

agar bisa digunakan sebagai input dari fully-connected layer yang kemudian diberi fungsi dense. Dense adalah fungsi untuk menambahkan layer pada fully-connected.

model.add(Dense (128, activation='relu')) \#fully connected la

Gambar 6. Fully Connected Layer

Pada gamabar diatas dense yang digunakan adalah sebanyak 128 unit. Unit tersebut merupakan jumlah node yang harus ada di hidden layer yang mempunyai nilai antara jumlah input node dan output node. Sedangkan untuk fungsi aktivasinya digunakan fungsi ReLU. Fungsi dari fully Connected layer ini adalah untuk melakukan transformasi pada dimensi data agar data dapat diklasifikasikan secara linear.

model.add(Dense(7, activation='softmax')) \#softmax works

Gambar 7 Fully Connected Layer Akhir

\subsection{Akurasi}

Setelah melewati beberapa tahap pemodelan, kemudian model tersebut diuji nilai akurasi dan lossnya dengan menggunakan adam optimizer

epochs $=100$

model. compile(loss='categorical_crossentropy', optimizer='Adam', metrics=['accuracy']) history = model.fit(X_train, y_train, validation_data=(X_test, y_test), epochs=epochs, batch_size $=32$ ) \#Final evaluation of the model

Gambar 8. Uji Akurasi

Dengan menggunakan iterasi epoch sebanyak 100 selajutnya hasil akurasi validasi yang didapatkan adalah sebagai beriukut:

loss: 0.0259 - accuracy: 0.9907 - val_loss: 0.1895 - val_accuracy: 0.9490

Accuracy: $94.90 \%$

Gambar 9. Hasil Akurasi

Berdasarkan gambar 5.8 yang menunjukkan hasil akurasi model. Sehingga dapat diketahui besar loss 0.2\% dengan akurasi yang tinggi sebesar 99,07\% sedangkan 


\section{Journal of Software Engineering Ampera}

Vol. 1, No. 2, June 2020 e-ISSN: 2775-2488

https://journal-computing.org/index.php/journal-sea/index

untuk data validasi, nilai loss nya tidak terlalu tinggi yaitu sebesar 18,95\% dan akurasi sebesar 94,90\% yang menunjukkan akurasi model sebesar 94,90\%. Untuk klasifikasi dengan menggunakan banyak kelas yaitu sebanyak 7 kelas nilai akurasi yang didapat sebesar 94,90\% tersebut sudah bagus untuk dijalankan dan sistem sudah cukup pintar untuk mendeteksi batik sesuai dengan kelas yang ada. Dibawah ini merupakan paparan grafik gambar akurasi dan loss dari model training dan validasi:
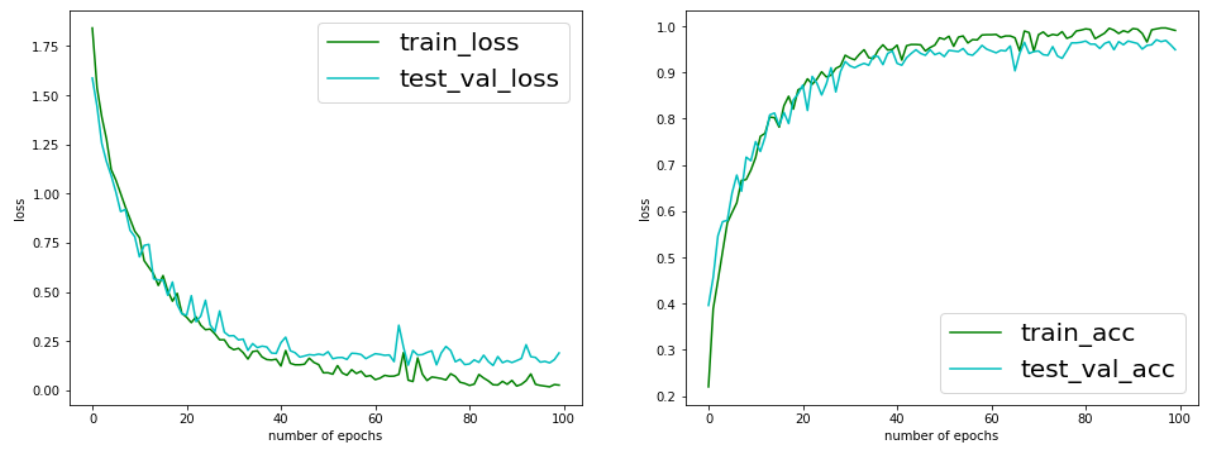

Gambar 10. Grafik Training Akurasi dan Training Loss

Pada gambar sebelah kanan diatas menunjukkan perbedaan akurasi antara hasil training dan validasi tidak terlalu signifikan. Pada epoch ke 30 menunjukkan data akurasi untuk data train cukup stabil hingga pada epoch ke 100. Sedangkan untuk data validasi mulai epoch ke 40 hingga epoch ke 100, nilai akurasi yang dihasilkan cukup stabil. Untuk gambar sebelah kiri nilai kesalahan untuk data training dimulai pada kisaran 1,50 untuk data train dan 0,50 untuk data validasi dan keduanya mulai stabil pada epoch ke 30 sampai ke epoch 100.

\subsection{Precision Recall}

$\exists$

precision recall f1-score support

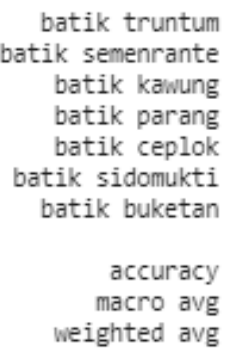

0.99

0.94

0.97

108

0.89

0.99

0.94

121

0.97

0.76

$0.86 \quad 97$

0.96

0.95

0.95

0.97

111

0.95

0.99

95

0.98

1.00

0.96

116

0.95
0.95

0.99

0.95

0.95

0.95

0.95

Gambar 11. Precision Recall 


\section{Journal of Software Engineering Ampera}

Vol. 1, No. 2, June 2020 e-ISSN: 2775-2488

https://journal-computing.org/index.php/journal-sea/index

Pada gambar diatas dapat kita lihat bahwa precesion (tingkat ketepatan) menghasilkan ketepatan yaitu untuk batik truntum sebesar $99 \%$, batik semenrante 89\%, batik kawung 97\%, batik parang 96\%, batik ceplok 95\%, batik sidomukti 98\%, dan batik buketan 93\%. Sedangkan untuk recall (tingkat keberhasilan) menghasilkan keberhasilan yaitu untuk batik truntum sebesar 99\%, batik semenrante $89 \%$, batik kawung 97\%, batik parang 96\%, batik ceplok 95\%, batik sidomukti $100 \%$, dan batik buketan $99 \%$.

\subsection{Hasil Prediksi untuk Deteksi Persatu Gambar}

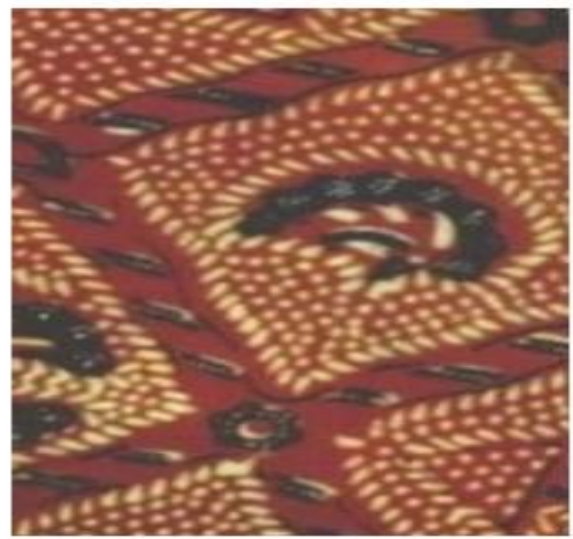

$\nabla y$

[. $\operatorname{array}([[3.7572228 \mathrm{e}-08,9.6105159 \mathrm{e}-09,9.3996841 \mathrm{e}-06,5.0368293 \mathrm{e}-15$, $3.6882419 e-16,9.9998987 e-01,7.5951971 e-07]]$, dtype=float32)

[39] print( labels[np.argmax(y)], np.max(y))

[ batik sidomukti 0.99998987

Gambar 12. Hasil Prediksi gambar

Hasil prediksi untuk deteksi persatu gambar bisa dilihat pada gambar 5.11. Variabel y merupakan nilai hasil daril prediksi yang menghasilkan banyak nilai dari masingmasing kategori. Ada 7 kategori kelas yang telah di labelkan bisa kita lihat nilai terbesarnya ada pada kolom ke 6 yang merupakan kelas batik sidomukti berdasarkan label yang sudah di definisikan. Hasil dari diprediksi untuk mendeteksi gambar tersebut adalah benar bahwa gambar tersebut merupakan batik sidomukti dengan nilai probabilitas tertinggi yaitu 0,99\%. 


\section{Journal of Software Engineering Ampera}

Vol. 1, No. 2, June 2020 e-ISSN: 2775-2488

https://journal-computing.org/index.php/journal-sea/index

\subsection{Evaluasi dan Prediksi Hasil Train dan Test dari Seluruh Kelas}

Untuk melihat hasil prediksi dari data training dan data testing akan ditunjukkan melalui tabel confusion matrix seperti gambar dibawah ini.

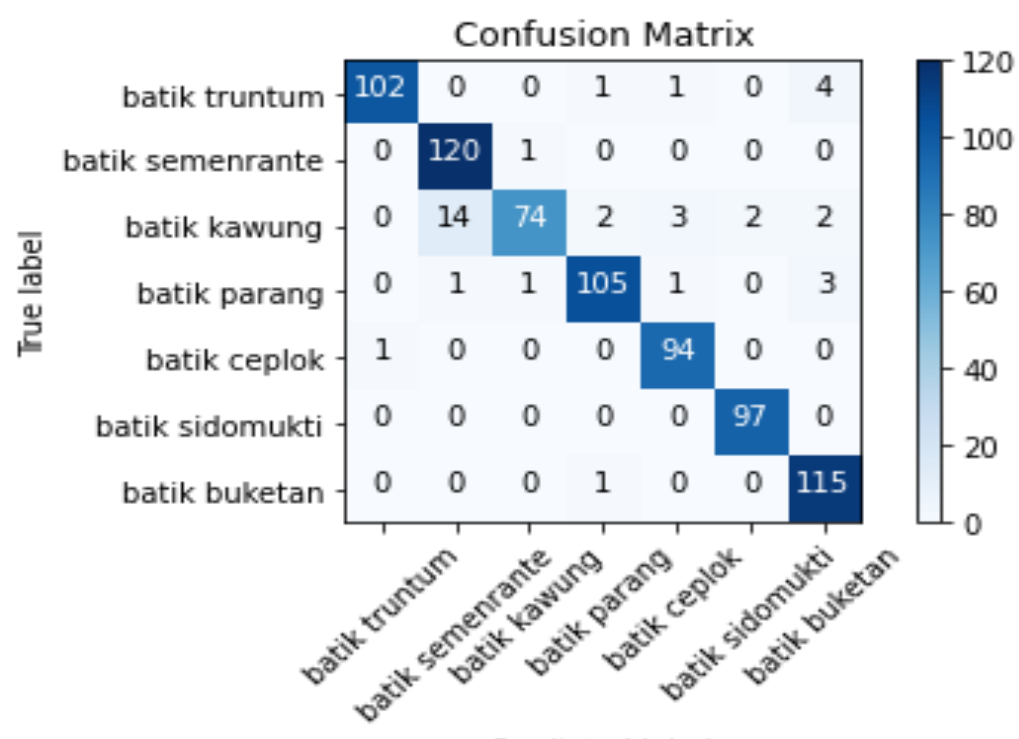

Predicted label

\section{Gambar 13. Hasil Klasifikasi Data Baru}

Gambar diatas merupakan hasil dari prediksi data baru, dimana dapat dilihat prediksi yang didapat bahwa dari 745 data gambar yang dimasukkan komputer semua data berhasil di klasifikasi dengan baik. Pada batik truntum data yang dimasuk sebanyak 103 gambar yang berhasil di klasifikasi adalah sebanyak 102 benar dan 1 salah, batik semenrante data yang dimasukkan sebanyak 135 yang berhasil diklasifikasi dengan benar sebanyak 120 dan 15 salah, batik kawung data yang dimasukkan sebanyak 76 yang berhasil diklasifikasi dengan benar sebanyak 74 dan 2 salah, batik parang data yang dimasukkan sebanyak 109 yang berhasil diklasifikasi dengan benar sebanyak 105 dan 4 salah, batik ceplok data gambar yang dimasukkan sebanyak 99 yang berhasil diklasifikasin dengan benar sebanyak 94 dan 5 salah, batik sidomukti data yang dimasukkan sebanyak 99 yang berhasil diklasifikasi dengan benar sebanya 97 dan salah, dan batik buketan data yang dimasukkan sebanyak 124 yang berhasil diklasifikasi dengan benar sebanyak 115 dan 9 salah. Dari penelitian yang di lakukan, hasil akurasi yang didapatkan dari data trining dan testing menghasilkan akurasi yang cukup bagus. Maka dapat dikatakan bahwa metode ini sangat baik untuk melakukan klasifikasi gambar batik. 


\section{KESIMPULAN}

Berdasarka pembahasan yang telah dilakukan, maka dapat disimpulkan bahwa Pembuatan model klasifikasi data citra motif batik solo telah berhasil dilakukan dengan menggunakan metode deep learning yang berarsitektur Convolutional Neural Network (CNN). Model CNN pada penelitian ini menggunakan input shape berukuran $32 \times 32 \times 3$, ukuran filter $3 \times 3$, jumlah epoch sebanyak 100. Data yang digunakan untuk proses training model sebanyak 2256 menghasilkan tingkat akurasi training dan testing dalam melakukan deteksi gambar citra batik solo sebesar 99\% untuk accuracy dan 94\% untuk validasi accuracy Penelitian ini menggunakan data testing baru sebanyak 745 gambar dimana perkelas terdapat 96 sampai 127 gambar untuk diuji kedalam model yang telah dibuat. Hasil testing menghasilkan tingkat akurasi baru dalam mengklasifikasi motif citra batik solo yaitu sebesar $95 \%$.

\section{DAFTAR PUSTAKA}

Goodfellow, I., Bengio, Y., dan Courville, A. 2016. Deep Learning. Diperoleh pada 25 Januari 2018 dari http://goodfeli.github.io/dlbook/.

Lestari, S. D. (2012). Mengenal Aneka Batik. PT Balai Pustaka (Persero).

Hutchison, D., Kanade, T., Kittler, J., Kleinberg, J. M., Mattern, F., Mitchell, J. C., Naor, M., Nierstrasz, O., Pandu Rangan, C., Steffen, B., Sudan, M., Terzopoulos, D., Tygar, D., Vardi, M. Y., Weikum, G., Scherer, D., Müller, A., \& Behnke, S. (2010). Evaluation of Pooling Operations in Convolutional Architectures for Object Recognition. In K. Diamantaras, W. Duch, \& L. S. Iliadis (Eds.), Artificial Neural Networks - ICANN 2010 (Vol. 6354, pp. 92-101). Springer Berlin Heidelberg. https://doi.org/10.1007/978-3-642-15825-4_10

Putri, R. A., \& Rochmawati, N. (2019). Penerapan Algoritma Support Vector Machine untuk Klasifikasi Motif Citra Batik Solo Berdasarkan Fitur MultiAutoencoders. 01, 8.

RISMIYATI, \& M.t, D. A. S. (2016). IMPLEMENTASI CONVOLUTIONAL NEURAL NETWORK UNTUK SORTASI MUTU SALAK EKSPOR BERBASIS CITRA DIGITAL [Universitas Gadjah Mada]. http://etd.repository.ugm.ac.id/index.php?mod=penelitian_detail\&sub= PenelitianDetail\&act=view\&typ=html\&buku_id=101746\&obyek_id=4

Sugiyono. 2016. Metode Penelitian Kuantitatif, Kualitatif dan R\&D. Bandung: PT Alfabet. 